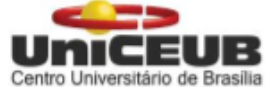

CENTRO UNIVERSITÁRIO DE BRASÍLIA - UniCEUB FACULDADE DE TECNOLOGIA E CIÊNCIAS SOCIAIS APLICADAS

PROGRAMA DE INICIAÇÃO CIENTÍFICA
\end{abstract}

HENRIQUE TORRES DE LIMA

LUCAS GUILHERME BADONA DE CARVALHO

ANÁLISE DE TRAVESSIAS DE PEDESTRES EM VIAS ARTERIAIS POR MEIO DO SOFTWARE ANYLOGIC

BRASÍLIA-DF

2018 


\section{$=$ \\ LUCAS GUILHERME BADONA DE CARVALHO \\ HENRIQUE TORRES DE LIMA}

\section{ANÁLISE DE TRAVESSIAS DE PEDESTRES EM VIAS ARTERIAIS POR MEIO DO SOFTWARE ANYLOGIC}

Relatório final do Programa Institucional de Bolsas de Iniciação Científica e Tecnológica apresentado à Assessoria de Graduação e Pesquisa pela Faculdade de Tecnologia e Ciências Sociais Aplicadas - FATECS

Orientação: Prof. a Dra. Ana Paula Borba Gonçalves Barros

\section{BRASÍLIA-DF}

2018 


\section{AGRADECIMENTOS}

Nunca é demais lembrar o peso e o significado dos gestos de solidariedade das pessoas que estiveram ao nosso lado durante essa pesquisa, e claro, acima de tudo demonstrar-Ihes a devida gratidão por tornarem possível a realização dessa etapa em nossas vidas.

E é nesse espírito de agradecimento que faço questão de memorar nosso ilustre Professor João Marcos, que além dos diversos ensinamentos em sala de aula, foi capaz de abrir nossos olhos para o amplo universo acadêmico e sem medir esforços nos mostrou que a curiosidade, a criatividade e a busca pelo saber não possuem limites e mais do que isso, formam os alicerces de qualquer pesquisador.

Sem dúvida nenhuma seria um trabalho impossível discutir sobre as virtudes dessa profissão, sem mencionar a pessoa, que talvez, atuou na fração mais trabalhosa dessa pesquisa, a nossa querida Orientadora Ana Paula, que por mais vezes que posso contar nos apontou a direção, e sempre esteve à disposição para nos aconselhar e corrigir quando necessário.

Não poderia esquecer de dar os créditos a àqueles que ofereceram os meios dessa pesquisa, por isso agradecemos a Assessoria de Pós-Graduação e Pesquisa, pela manutenção desse programa e por acolher tantos alunos, que muitas vezes, como nós, só tinham a vontade de aprender a oferecer.

E pensando nos alunos, agradecemos aos voluntários, Antônio, Bruno, Carolina, Douglas, Gabriel, Gustavo, João Paulo, Lucas, Mateus, Matheus, Paulo Sergio, Ronaldo, Samuel, e Vitor por aceitarem a dura tarefa de acordar cedo e ir a campo conosco para coletar os dados essenciais desse trabalho.

Deixando de lado o âmbito acadêmico, gostaria de reforçar a gratidão aos nossos amigos e familiares, pelo apoio, carinho e amor, que sempre se mantiveram presentes, nos ajudando a fugir um pouco das complicações de uma pesquisa científica. 


\title{
ANÁLISE DE TRAVESSIAS DE PEDESTRES EM VIAS ARTERIAIS POR MEIO DO SOFTWARE ANYLOGIC
}

Henrique Torres de Lima - UniCEUB, PIBIC Institucional, aluno bolsista, henryt1216@gmail.com

\author{
Lucas Guilherme Badona de Carvalho - UniCEUB, PIBIC Institucional, \\ aluno bolsista, lucas-badona1@outlook.com
}

Ana Paula Borba Gonçalves Barros - UniCEUB, professora orientadora

ana.barros@uniceub.br

\section{Resumo}

É notório que, na grande maioria das cidades brasileiras, há uma ausência de interesse em relação aos pedestres, por parte do poder público, uma vez que o foco das ações volta-se ao tráfego motorizado (principalmente o individual), 0 que acaba por desestimular que as pessoas utilizem os espaços públicos como pedestres nos seus deslocamentos. Esta falta de interesse se reflete nos tempos semafóricos, nos quais, quase sempre, a prioridade para a maior fluidez é destinada ao motor e não às pessoas. Neste contexto, este trabalho visa verificar em que medida a inserção de estratégias de moderação de tráfego - no caso deste estudo, as faixas de pedestres semaforizadas - pode auxiliar nos deslocamentos dos pedestres em vias arteriais, de modo a aumentar a sua segurança. Para tanto, o estudo de caso insere-se no Plano Piloto de Brasília, mais precisamente no fim da via arterial W3 norte, onde se localizam distintos Polos Geradores de Viagem (PGV), como o Boulevard Shopping, o Hipermercado EXTRA e o Setor Hospitalar Local Norte (SHLN). Como metodologia de estudo, optou-se pela simulação da situação real (simulação descritiva) e da proposta (simulação prescritiva) utilizando o software AnyLogic, que além de apresentar uma interface gráfica que premite a modelagem rápida de ambientes complexos como o comportamento entre elementos motorizados e não motorizados, consegue-se utilizar a versão de estudante da ferramenta disponível na internet. Para a modelagem, iniciou-se com a realização do mapeamento do trecho estudado, tanto no âmbito da caracterização da rede número de faixas de rolamento, velocidade máxima permitida -, como no âmbito da caracterização dos agentes - contagem veicular e de pedestres. Para a primeira contagem, foram mobilizados onze alunos voluntários posicionados estrategicamente em onze pontos ao longo da malha viária, em que contabilizaram durante 30 minutos a quantidade de automóveis (ônibus e carros) que trafegaram no trecho, nos horários de pico da manhã e da tarde, em um mesmo dia da semana. Para a segunda, procedeu-se a contagem com base no Método dos Portais (UCL - University College London) em que observou as linhas de desejo dos pedestres tanto em nas faixas de pedestres como fora delas durante os mesmos horários de pico e também em um único dia da semana. Como achados, verificou-se que na simulação descritiva o maior tempo médio de espera foi dos ônibus $(300,35$ s), em seguida dos pedestres $(214,13 \mathrm{~s})$ e 0 menor dos carros $(179,35 \mathrm{~s})$, o que ratifica o foco dado aos veículos motorizados individuais. De modo a melhorar o tempo de espera dos pedestres, na simulação prescritiva, procede-se à inserção de uma faixa semaforizada, demandando o 
deslocamento de 30 metros do retorno sentido leste-oeste (SHLN - Shopping) em direção à Ponte do Bragueto, havendo, assim, a inversão dos tempos entre pedestres $(142,81 \mathrm{~s})$ e carros $(265,99)$ e ônibus sendo pouco significativo $(292,72 s)$. Com isso, obteve-se uma redução do tempo de espera dos pedestres, bem como, uma travessia mais segura, justamente no ponto de maior fluxo de pedestre fora da faixa, indo ao encontro do que se espera para as cidades para pessoas (Gehl, 2010).

Palavras-chaves: Polos Geradores de Viagem. Simulação. AnyLogic. Pedestres. Brasília. 


\section{SUMÁRIO}

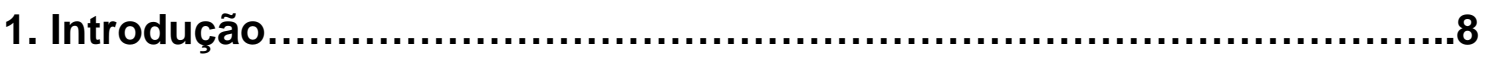

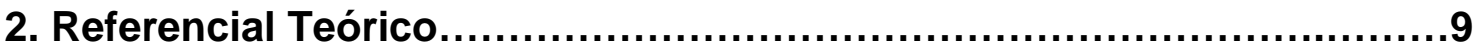

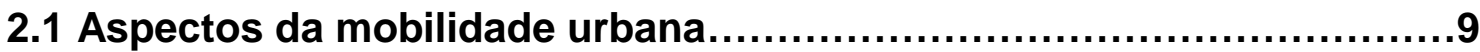

2.2 Modelagem Matemática...................................................11

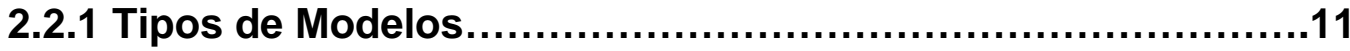

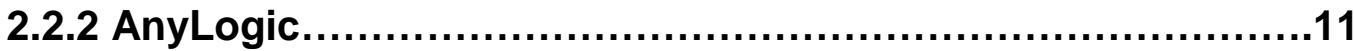

2.2.3 Nível de Serviço.......................................................12

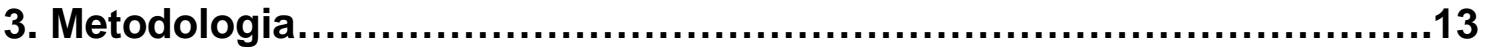

3.1 Caracterização da área de estudo....................................13

3.2. Contagem Volumétrica...............................................14

3.2.1 Contagem Veicular...........................................14

3.2.2 Contagem de Pedestres......................................15

3.3 Dados da malha viária.....................................................

3.4 Simulação Computacional...............................................16

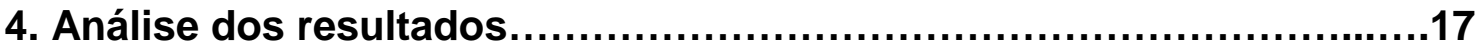

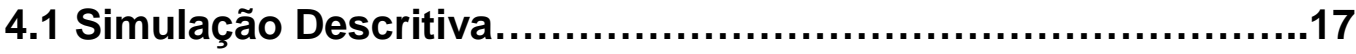

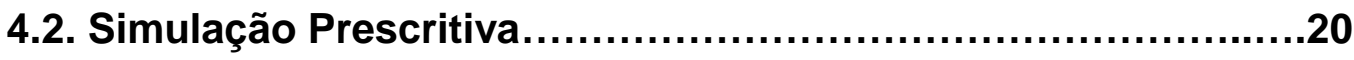

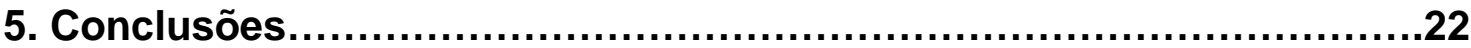

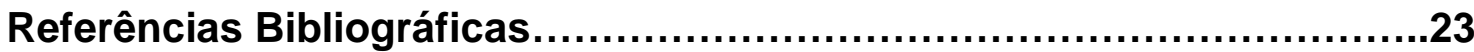




\section{LISTAS DE FIGURAS}

Figura 1: Delimitação da área de estudo...........................................

Figura 2: Polos geradores de viagem presentes na área de estudo..................14

Figura 3: Delimitação dos trechos de contagem veicular............................... 15

Figura 4: Principais rotas de travessias dos agentes não motorizados.................16

Figura 5: Exemplo de um dos fluxogramas do sistema (ônibus) ........................18

Figura 6: Código Java para interação dos modos.....................................19

Figura 7: Alterações da estrutura física da malha....................................

\section{LISTA DE TABELAS}

Tabela 1: Parâmetro de determinação do nível de serviço ...............................13

Tabela 2: Contagem de veículos utilizada na simulação ............................17

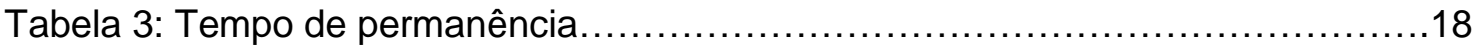

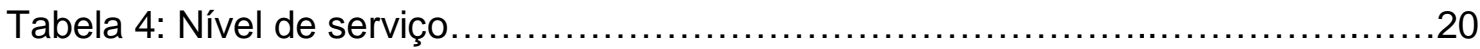

Tabela 5: Tempo de permanência (Solução) ......................................21 


\section{INTRODUÇÃO}

Percebe-se, em muitos trechos viários urbanos, o crescente aumento do número de automóveis, que acaba por gerar congestionamentos, causando desconforto tanto para os usuários motorizados quanto aos não motorizados. Desta maneira, o incentivo ao uso do transporte coletivo público e a uma sinalização eficaz é de importância ímpar para um sistema viário fluido e seguro a todos os modos nela presente.

A forma da cidade de Brasília, na qual o transporte motorizado teve um enfoque maior, uma vez que a sua criação foi baseada no Pensamento Modernista (Costa, 1991) - com a presença de grandes vazios urbanos - provocou o aumento das distâncias percorridas por qualquer modo de transporte, e, por conseguinte, fomentou o conflito entre carros e pedestres em diversos pontos da cidade justamente por não haver a equidade infra estrutural adequada no espaço urbano. Assim sendo, muitos desses agentes não motorizados (pedestres), por consequência desta ausência ou inadequação na infraestrutura pedonal, que deveria diminuir as distâncias percorridas para atingirem os seus destinos, acabam por escolher travessias perigosas e não apropriadas para sua locomoção.

Cabe destacar que alguns autores (MEDEIROS, 2013; BARROS et al., 2017) afirmam que a forma urbana interfere sobremaneira o desempenho das cidades em termos de deslocamentos. Neste contexto, cabe apontar que a forma do Plano Piloto de Brasília tende a estimular o aumento das velocidades inferidas pelos motoristas, principalmente em vias de grande fluxo motorizado, tal como as arteriais (a exemplo da W3, que se trata de um corredor de ônibus).

Este aumento de velocidade também é estimulado pela inadequada localização de Polos Geradores de Viagem (PGV) de dimensões significativas em regiões com capacidade viária aquém do desejável ou mesmo em locais com uma concentração exagerada destes equipamentos urbanos, o que dificulta a acessibilidade aos pedestres e tornando necessária uma intervenção viária destas áreas, uma vez que, existe um desequilíbrio nos modos do sistema (PORTUGAL, 2012; KNEIB, 2004). 
Com base no exposto acima, a presente pesquisa visa verificar em que medida a inserção de estratégias de moderação de tráfego (como faixas semaforizadas) pode auxiliar nos deslocamentos dos pedestres sem alterar significativamente 0 desempenho dos modos motorizados em vias arteriais. Para tanto, utilizou-se o software AnyLogic na construção de dois modelos comparativos - um descritivo, em que apresenta o cenário atual da área de estudo, e um prescritivo, que apresenta o cenário futuro (descritos a seguir).

\section{REFERENCIAL TEÓRICO}

\subsection{ASPECTOS DA MOBILIDADE URBANA}

Sabe-se que a mobilidade urbana deve levar em consideração não somente a macro escala - transporte de massa - como também a micro - mobilidade ativa -, pois o fato destes se retroalimentarem faz com que ambos sejam relevantes para o desempenho de qualquer cidade, no entanto, verifica-se que, em muitos casos, essa última tem sido deixada de lado (GEHL, 2010).

Assim sendo, no que tange a mobilidade ativa, dois autores merecem destaque: Jacobs (2000) e Gehl (2010), por focarem o aspecto da vida urbana, ou seja, creem que havendo pessoas no espaço público por uma longa permanência, pode tornar o espaço mais vivo e seguro, desestimulando, portanto, o uso massivo dos modos motorizados individuais.

Assim, para que haja a diversidade desejada de pessoas nos espaços públicos urbanos, Jacobs (2000) acredita que tais espaços devem atender a 4 condições:

a) Diversidade de usos - o fato de haver distintos usos e ocupação do solo misto (comércios, serviços, residências, etc.), possibilita que haja vida em distintos horários do dia em dada região da cidade;

b) Quadras curtas - quanto menor o tamanho das quadras (quarteirões), maior a possibilidade de encontros e de sucesso econômico da área, tendo em conta a maior quantidade de esquinas;

c) Distintas idades dos edifícios - presença de edifícios antigos juntamente com novos, permite que haja maior diversidade de perfis e faixas etárias tanto residindo quanto trabalhando no espaço urbano; 
d) Alta concentração de pessoas - havendo densidade relativamente alta nos espaços, aumenta a probabilidade de um maior quantitativo de pessoas estarem presentes nas ruas.

À vista disso, se tem o interesse de melhorar o transporte urbano para os pedestres, tendo em vista que com a facilitação de sua movimentação haverá um incentivo para a mobilidade e o fluxo de pessoas, tornando, assim, o ambiente mais seguro, e favorecendo a economia e a diversidade social.

Aliado às ideias de Jacobs (2000), Gehl (2010) desenvolve o pensamento sobre como projetar uma cidade que consiga atender, à priori, a vida das pessoas; e, mais importante, como esta cidade consegue moldar o comportamento das pessoas (HILLIER e HANSON, 1984).

Para tanto, Gehl (2010) acredita que as cidades devem ser vivas, seguras, saudáveis e sustentáveis, ou seja, quanto mais pessoas nas ruas, mais vida haverá; e havendo mais vida, consequentemente, haverá mais segurança (os "olhos da rua", nomeado por Jacobs, 2000); atraindo mais pessoas às ruas, estas caminharão mais, e, portanto, serão mais saudáveis, o que automaticamente tonará a cidade mais sustentáveis, tendo em vista, haver um desestímulo ao uso dos veículos motorizados.

Neste contexto, verifica-se um planejamento equivocado das cidades ao ampliar ou construir vias e estacionamentos, visto que com isso a tendência é aumentar o volume de tráfego estimulado pela respectiva infraestrutura de transporte. Dessa forma, qualquer espaço residual disponível nas cidades tende a ser preenchido pelo estímulo recebido, neste caso, pelos automóveis.

De modo a combater tais tendências é imprescindível que o planejamento e o desenvolvimento de uma cidade deva compreender três escalas (GEHL, 2010):

a) A escala global do espaço urbano, isto é, a concepção de toda a cidade;

b) A escala da implantação dos edifícios, de modo a avir com a organização dos bairros;

c) E, por último, e mais importante no contexto da mobilidade ativa, a escala humana. 
Segundo o autor, o projeto que harmoniza estas três escalas, consegue, com facilidade, gerar um ambiente estimulador para o pedestrianismo. Sob este viés, cabe destacar que, Gehl (2010) acredita que na concepção de Brasília foi atribuída maior ênfase à primeira escala, uma vez que ao ser vista do céu mostra toda a sua monumentalidade e estética. Por outro lado, esta última escala (humana) foi esquecida, afinal, ao ser vista e vivida do chão, parece se estar em uma maquete fora de escala, onde tudo parece fora de proporção, em que as distâncias demonstram ser quase impossíveis de serem percorridas a pé, tornando-a uma cidade sem vida.

\subsection{MODELAGEM MATEMÁTICA}

\subsubsection{TIPOS DE MODELO}

Para a realização desta pesquisa, faz-se necessário a compreensão e aplicação de três modelos matemáticos:

a) O descritivo, gerado para descrever um sistema, isto é, o que está acontecendo no objeto de estudo, em que pode ser utilizado simulações computacionais para melhor descrever a realidade, ou descrever um modelo idealizado.

b) O preditivo, que consiste na análise do modelo descritivo e dos dados coletados, além da elaboração de hipóteses de como o sistema se comporta com a alteração desses dados, buscando sempre responder o que poderia acontecer no sistema.

c) E, por fim, o modelo prescritivo, cuja característica é procurar saber, dentre todas as possíveis intervenções, qual a que aprimora com maior adequação o sistema.

\subsubsection{ANYLOGIC}

Neste contexto, insere-se o AnyLogic escolhido para a realização das simulações, visto ser uma ferramenta de desenvolvimento com uma interface gráfica que permite rapidamente modelar ambientes complexos como manufatura, lógica de negócios, recursos humanos, comportamento entre 
elementos motorizados e não motorizados entre outros. Utilizando-se de uma modelagem por fluxogramas, pouco explorado por outros softwares na área da mobilidade urbana, permite a montagem de sistemas complexos de forma mais intuitiva e detalhada.

Devido ao seu propósito - um programa capaz de simular vários cenários diferentes, por isso seu nome "Anylogic" traduzido literalmente como qualquer lógica -, o software apresenta simultaneamente uma galeria de pedestres e de carros, algo incomum para outros softwares e valioso para qualquer tipo de análise que visa a interação desses dois modos.

\subsubsection{NÍVEL DE SERVIÇO}

Para se conseguir vislumbrar qualquer tipo de projeto viário motorizado é imprescindível a consulta ao manual americano de capacidade das vias, o Highway capacity manual (HCM). Este classifica 6 tipos de nível de serviço de uma rua:

- Nível A: Fluxo livre;

- Nível B: Fluxo estável, mas a presença de outros veículos começa a ser notada;

- Nível C: Fluxo médio, as atitudes de um veículo passam a ser afetadas pelos outros;

- Nível D: Fluxo denso, com liberdades de manobras restritas;

- Nível E: Fluxo próximo a capacidade;

- Nível F: Fluxo Forçado.

O cálculo desse nível de serviço leva em consideração a capacidade e o volume de veículos apresentado na via. Uma forma simples, porém, eficiente de calcular a capacidade é através da relação de Webster, que é dada por:

$$
F=525 \cdot L
$$

em que $\quad F: \quad$ fluxo de saturação [veículos];

$L: \quad$ largura da via [metros]; 
Para vias semaforizadas, aplica-se um fator de correção, dado por:

$$
C=F \cdot \frac{g s}{T}
$$

em que $\quad C$ : $\quad$ capacidade da via [veículos];

$F: \quad$ fluxo de saturação [veículos];

gs: tempo efetivo de verde do semáforo [seg];

T: tempo de ciclo do semáforo [seg];

\begin{tabular}{ll}
\hline Volume/capacidade & Nível de Serviço \\
\hline$<0.1$ & $\mathrm{~A}$ \\
Entre 0.1 e 0.3 & $\mathrm{~B}$ \\
Entre 0.1 e 0.3 & $\mathrm{C}$ \\
Entre 0.1 e 0.3 & $\mathrm{D}$ \\
Entre 0.1 e 0.3 & $\mathrm{E}$ \\
$>1$ & $\mathrm{~F}$ \\
\hline Tabela 1: Parâmetro de determinação do nível de serviço.
\end{tabular}

\section{METODOLOGIA}

\subsection{CARACTERIZAÇÃO DA ÁREA DE ESTUDO}

A região escolhida para a execução do projeto foi o trecho final da via W3 Norte, ilustrada na Figura 1, uma via arterial situada no Plano Piloto de Brasília. O local apresenta elevado fluxo de veículos motorizados e de pessoas por se tratar de uma via arterial que conecta outras regiões administrativas do Distrito Federal ao Plano Piloto. 


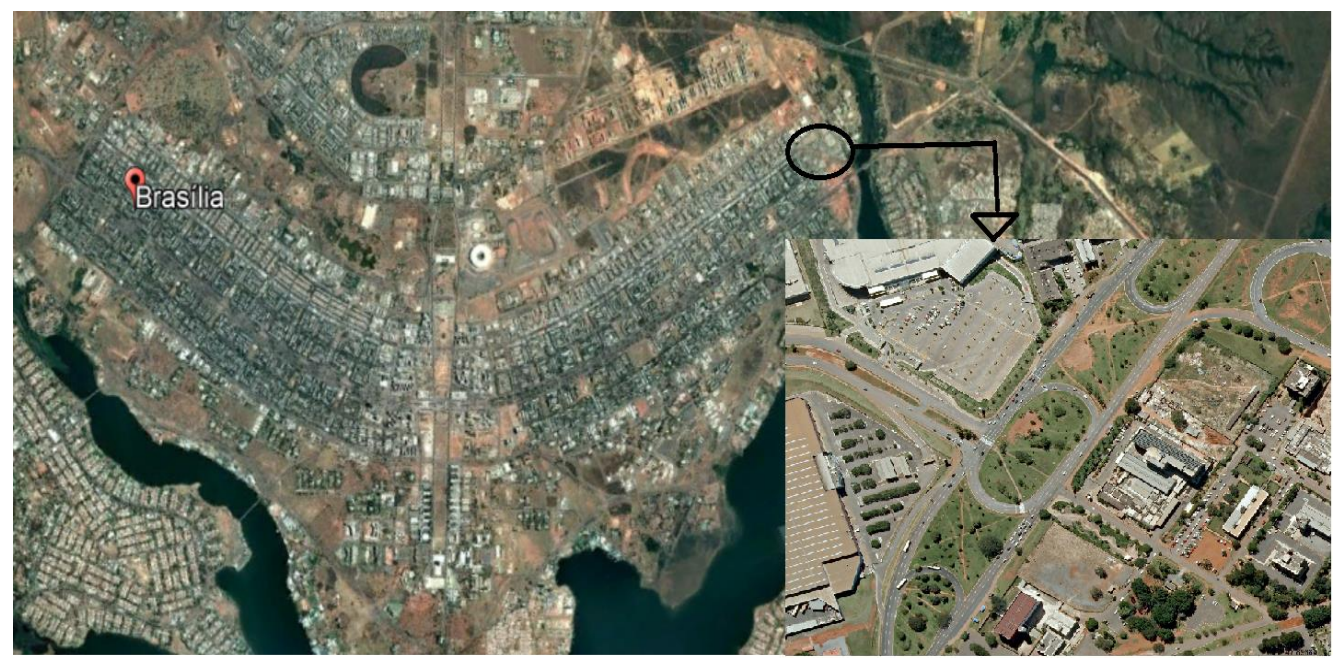

Figura 1: Delimitação da área de estudo.

Fonte: CODEPLAN (2014)

A região foi escolhida pelo fato de existirem diversos Polos Geradores de Viagens (PGV's) às margens da via, como mostra a Figura 2, sem que a mesma oferecesse opções de travessia eficientes para os agentes não motorizados.

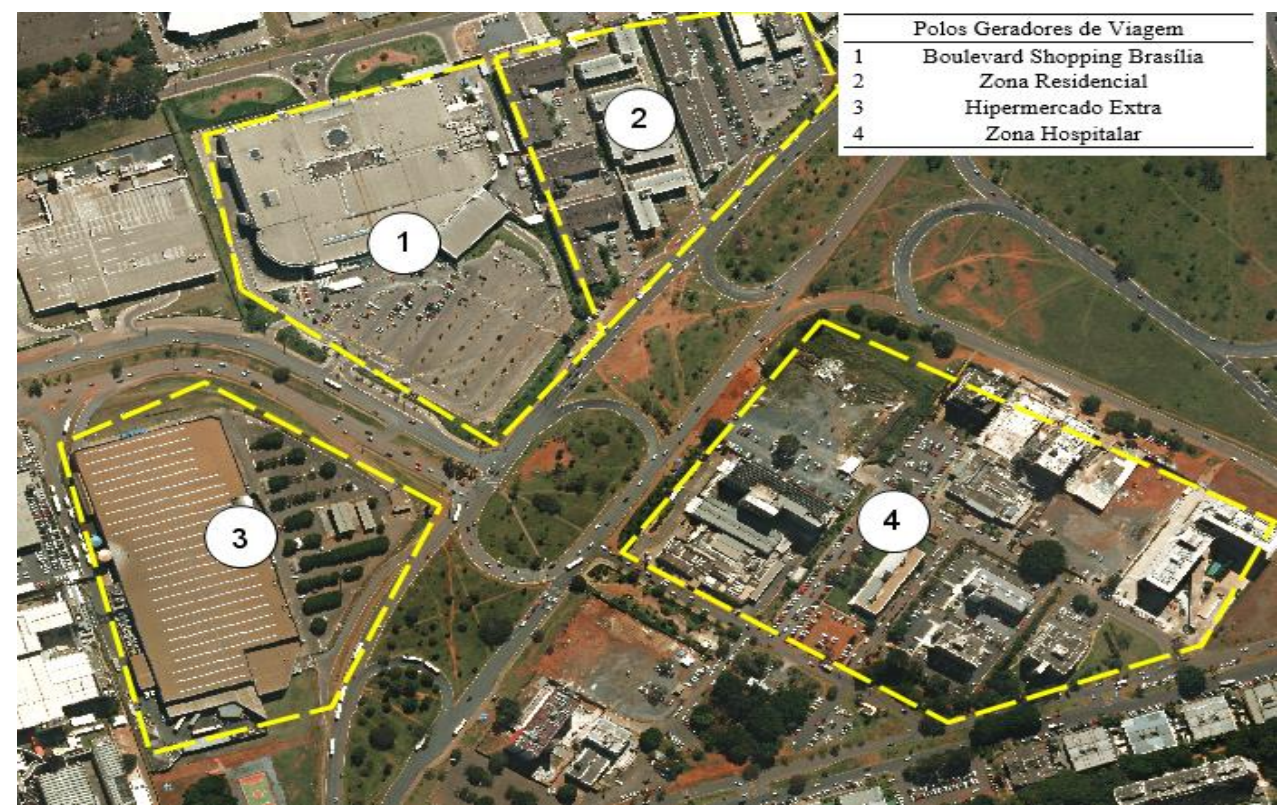

Figura 2: Polos geradores de viagem presentes na área de estudo

Fonte: CODEPLAN (2014)

\subsection{CONTAGEM VOLUMÉTRICA}

\subsubsection{Contagem veicular}

Para a realização da simulação, um dos principais dados de entrada no software é o volume de veículos e pedestres presente nas vias do local de estudo. Sendo 
assim, a contagem volumétrica dos veículos motorizados foi realizada em onze pontos estratégicos ao longo da malha viária, indicados na Figura 3 por círculos de cor vermelha e a partir dos pontos de contagem indicados, foi possível inferir a contagem volumétrica dos demais trechos (polígonos tracejados em branco) da região.

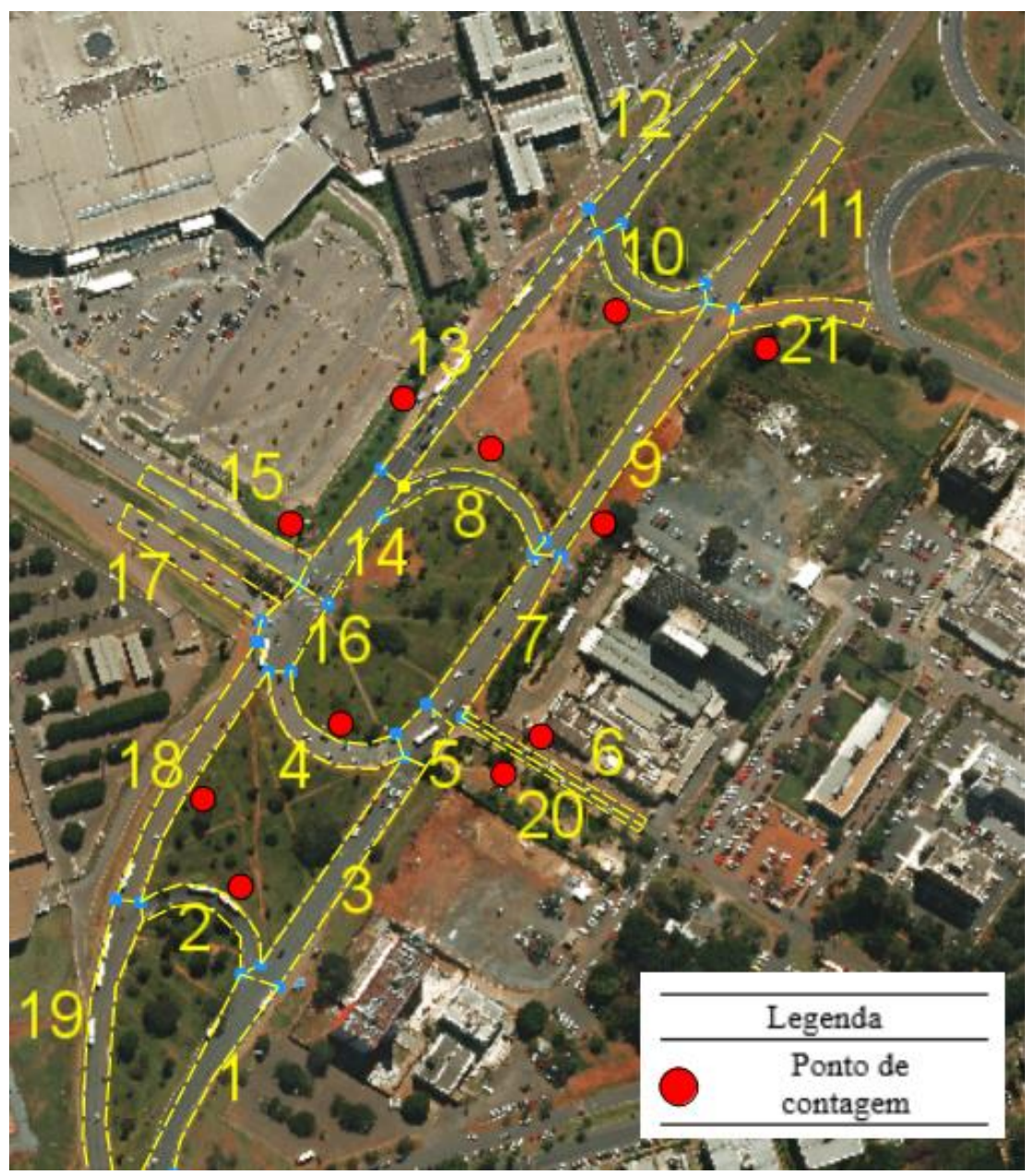

Figura 3: Delimitação dos trechos de contagem veicular.

Fonte: CODEPLAN (2014)

\subsubsection{Contagem de pedestres}

Para obtenção da contagem volumétrica dos pedestres, utilizou-se os dados de Braga (2017), no qual foi realizado um levantamento das linhas de desejo e o fluxo de pessoas entre os PGV's da área. Com essas informações, concentrouse essas travessias em seis principais rotas de desejo, como visto na Figura 4, a fim de diminuir o custo computacional para a simulação. 


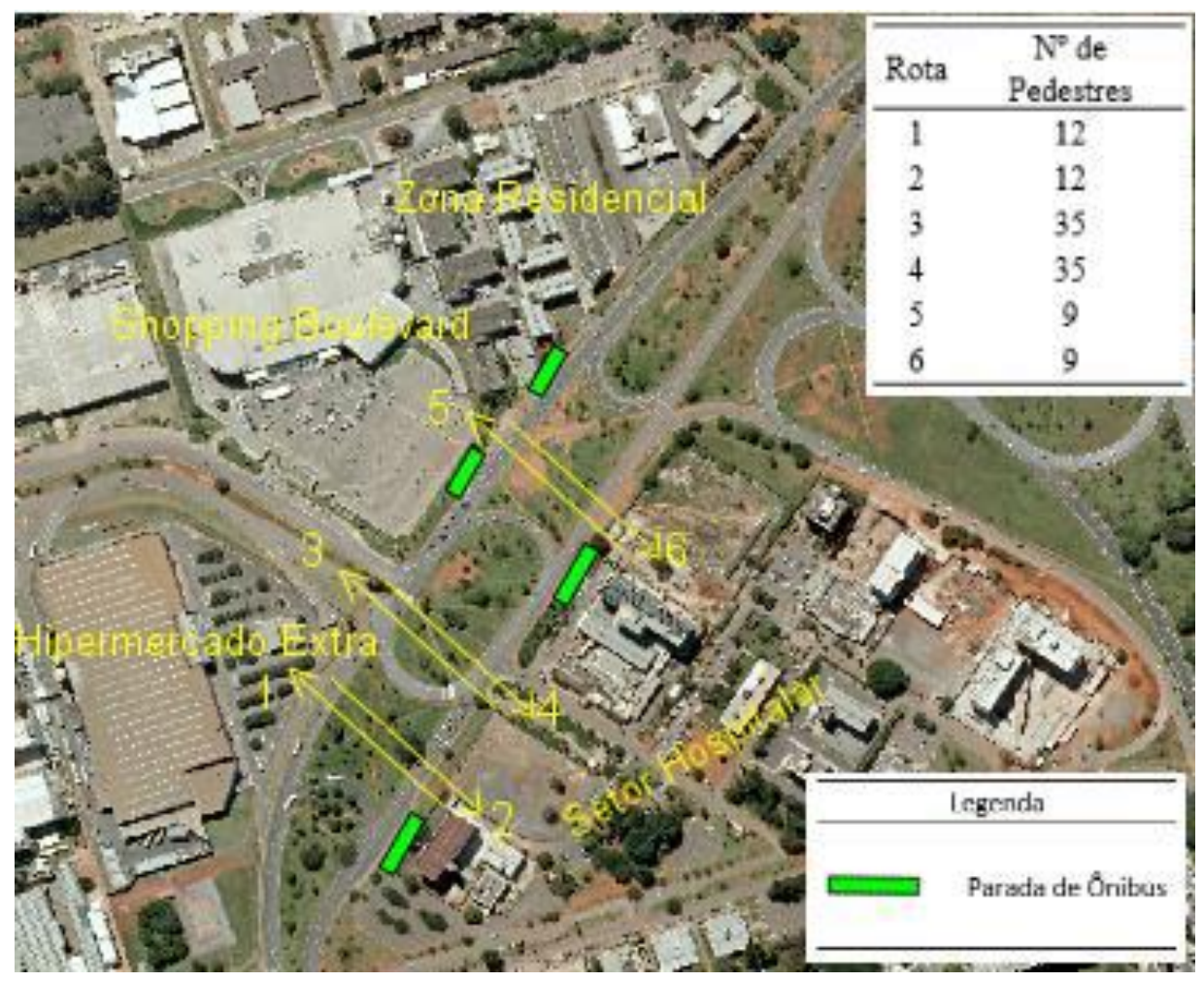

Figura 4: Principais rotas de travessias dos agentes não motorizados.

Fonte: CODEPLAN (2014)

\subsection{DADOS DA MALHA VIÁRIA}

Além da coleta de dados de agentes externos, a simulação da malha exige também, que seja feito um mapeamento do número de faixas de rodagem (de 4 a 5), semáforos (4), faixas de pedestres (4) e pontos de ônibus (4) da área de estudo.

\subsection{SIMULAÇÃO COMPUTACIONAL}

A partir dos dados de entrada coletados, é possível construir um modelo descritivo de simulação, e então calibrá-lo para uma representação fiel da realidade. Desta maneira, tendo em mãos uma ferramenta de comparação das possíveis propostas interventoras e métodos utilizados na avaliação de resultados, cria-se um modelo prescritivo que proponha mudanças na malha, a fim de julgar os efeitos das novas alterações e suas possíveis eventualidades. 


\section{ANÁLISE DOS RESULTADOS}

\subsection{SIMULAÇÃO DESCRITIVA}

Verifica-se, com base na Tabela 2, em que consta o número de veículos contabilizados no pico da manhã e da tarde nos trechos indicados na Figura 3, que na maioria das vezes o maior fluxo motorizado ocorre na parte da tarde, quer seja de veículos motorizados individuais ou coletivos, possivelmente por coincidir os horários de pico tanto da saída dos trabalhadores em geral com a troca de plantão dos médicos e horários de visitas no Setor Hospitalar Norte (Figura 4).

\begin{tabular}{|c|c|c|c|c|c|}
\hline \multicolumn{3}{|c|}{ Turno matutino (7:50-8:50) } & \multicolumn{3}{|c|}{ Turno vespertino (17:25-18:25) } \\
\hline Trecho & № de carros & $\begin{array}{l}\text { № de } \\
\text { ônibus }\end{array}$ & Trecho & $\begin{array}{l}\text { № de } \\
\text { carros }\end{array}$ & № de ônibus \\
\hline 1 & 1292 & 328 & 1 & 1990 & 226 \\
\hline 2 & 20 & 12 & 2 & 46 & 18 \\
\hline 3 & 1272 & 316 & 3 & 1944 & 208 \\
\hline 4 & 2136 & 16 & 4 & 1564 & 24 \\
\hline 5 & 3408 & 332 & 5 & 3508 & 232 \\
\hline 6 & 208 & 0 & 6 & 352 & 0 \\
\hline 7 & 3254 & 332 & 7 & 3666 & 732 \\
\hline 8 & 434 & 116 & 8 & 738 & 48 \\
\hline 9 & 2820 & 216 & 9 & 2928 & 684 \\
\hline 10 & 144 & 0 & 10 & 254 & 0 \\
\hline 11 & 2264 & 178 & 11 & 2352 & 670 \\
\hline 12 & 1104 & 116 & 12 & 1754 & 52 \\
\hline 13 & 960 & 116 & 13 & 1500 & 52 \\
\hline 14 & 1394 & 232 & 14 & 2238 & 100 \\
\hline 15 & 732 & 160 & 15 & 1380 & 60 \\
\hline 16 & 662 & 72 & 16 & 858 & 40 \\
\hline 17 & 2916 & 48 & 17 & 2464 & 172 \\
\hline 18 & 780 & 104 & 18 & 900 & 148 \\
\hline 19 & 800 & 116 & 19 & 946 & 166 \\
\hline 20 & 362 & 0 & 20 & 194 & 0 \\
\hline 21 & 700 & 38 & 21 & 830 & 14 \\
\hline
\end{tabular}

Tabela 2: Contagem de veículos utilizada na simulação. 
Esses dados foram inseridos no software e a partir deles foram gerados os fluxogramas logísticos, representados na Figura 5, que regem o modelo.

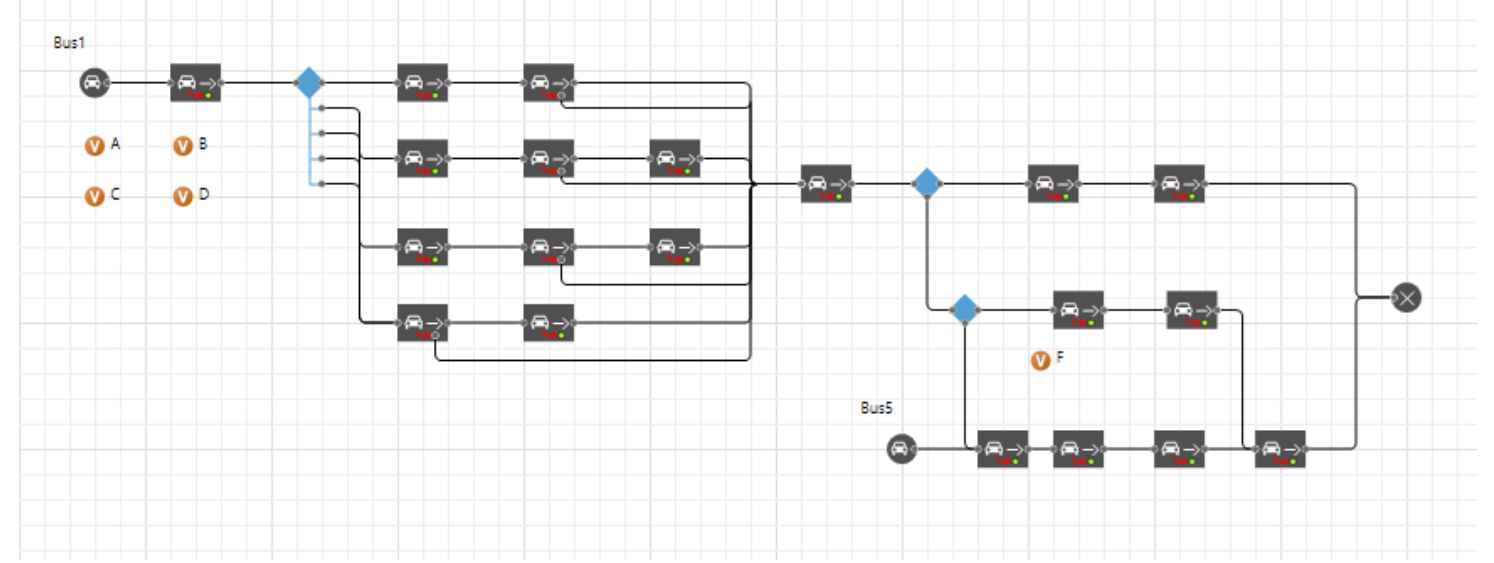

Figura 5: Exemplo de um dos fluxogramas do sistema (ônibus).

Fonte: AnyLogic (2018)

Apesar do software possuir galerias tanto para agentes motorizados quanto para não motorizados, a interação entre esses modos exige um rigor maior na modelagem. Isso porque, agentes de diferentes galerias ignoram a existência das demais. Dessa forma, foi preciso modelar um código Java, Figura 6, que verificasse a segurança dos agentes não motorizados, para que o mesmo autorizasse a travessia.

Por meio de ferramentas disponíveis no software, é possível obter o tempo de percurso dos agentes dentro da malha. A Tabela 3 apresenta o tempo de permanência média no sistema descritivo, o que se pode analisar que o tempo de permanência dos pedestres é maior que o dos veículos e menor que o dos ônibus, ratificando a prioridade que vem sendo dada aos modos motorizados individuais, o que vai de encontro ao que Jacobs (2000) e Gehl (2010) defendem.

\begin{tabular}{cc}
\hline Agente & Tempo de permanência médio (s) \\
\hline Pedestres & 214,13 \\
Carros & 179,35 \\
Ônibus & 300,35
\end{tabular}

Tabela 3: Tempo de permanência. 
Com base nas equações (1) e (2) e com os dados obtidos na contagem e na malha viária, obteve-se os níveis de serviço dos vinte e um trechos do modelo, como mostra a Tabela 4. Verifica-se que o nível de serviço da tarde foi, em média, maior que o da manhã, no entanto, não foi algo considerado muito significativo, uma vez que 9 trechos $(2,5,6,9,10,11,13,16$ e 19) mantiveram o mesmo nível, outros $9(1,3,7,8,12,14,15$ e 18) subiram apenas um nível e apenas 3 tiveram uma baixa de nível (4, 17 e 20).

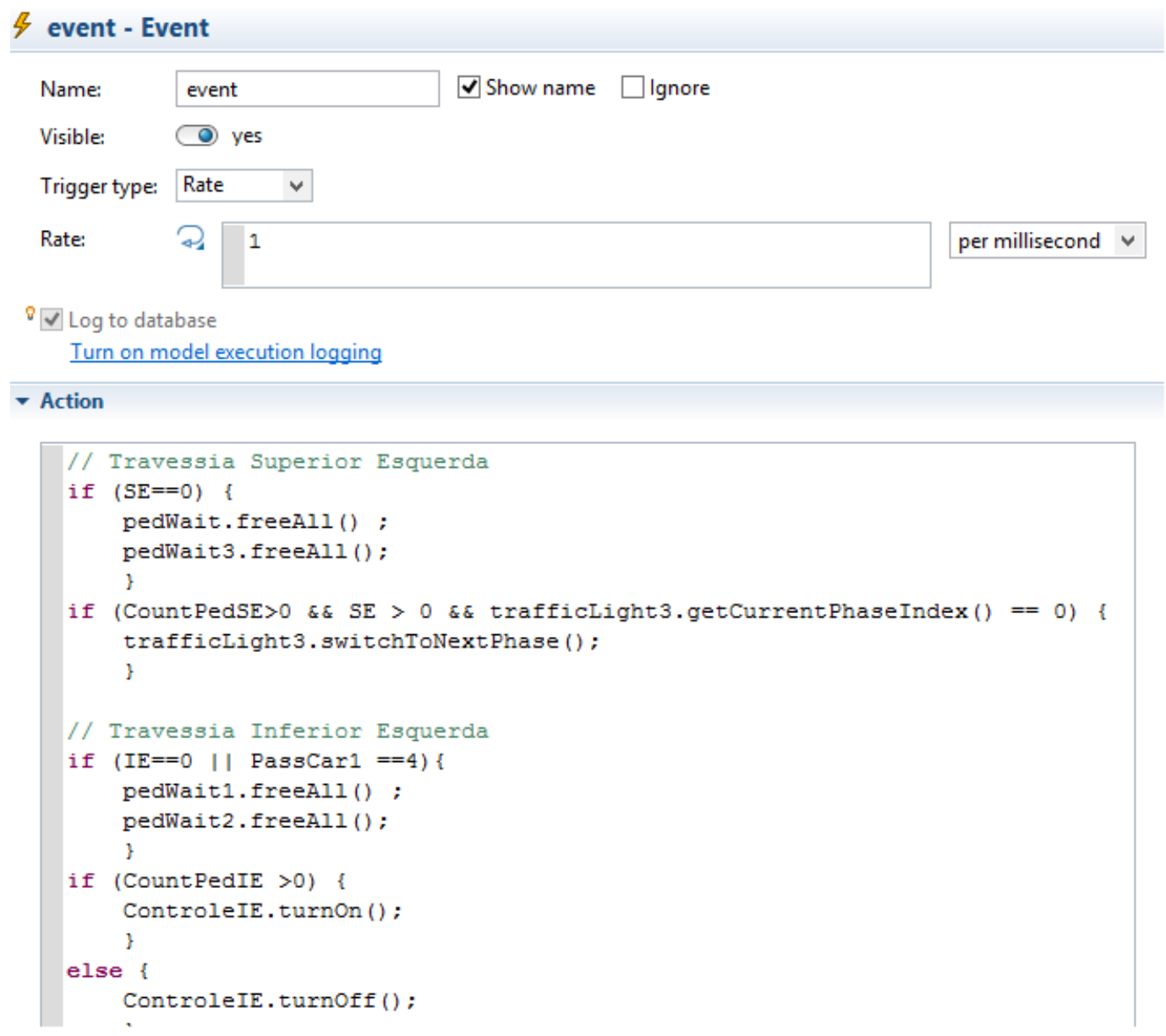

Figura 6: Código Java para interação dos modos.

Fonte: AnyLogic (2018) 


\begin{tabular}{|c|c|c|c|c|c|c|c|}
\hline $\begin{array}{l}\text { Trecho } \\
\text { da via }\end{array}$ & $\begin{array}{l}\text { Largura } \\
\text { (m) }\end{array}$ & $\begin{array}{l}\text { Fluxo de } \\
\text { Saturação }\end{array}$ & $\begin{array}{l}\text { Capac } \\
\text { idade }\end{array}$ & $\begin{array}{c}\text { Volume/ } \\
\text { capacidade } \\
\text { (matutino) }\end{array}$ & $\begin{array}{c}\text { Volume/ } \\
\text { capacidade } \\
\text { (vespertino) }\end{array}$ & $\begin{array}{l}\text { Nível de } \\
\text { Serviço } \\
\text { (matutino) }\end{array}$ & $\begin{array}{c}\text { Nível de } \\
\text { Serviço } \\
\text { (vespertino) }\end{array}$ \\
\hline 1 & 10,5 & 5512,5 & 2646 & 0,49 & 0,75 & C & D \\
\hline 2 & 7 & 3675 & 1764 & 0,01 & 0,03 & A & A \\
\hline 3 & 10,5 & 5512,5 & 2646 & 0,48 & 0,73 & C & D \\
\hline 4 & 10,5 & 5512,5 & 2646 & 0,81 & 0,59 & E & C \\
\hline 5 & 14 & 7350 & 3528 & 0,97 & 0,99 & $E$ & $E$ \\
\hline 6 & 7 & 3675 & 1764 & 0,12 & 0,20 & B & B \\
\hline 7 & 14 & 7350 & 3528 & 0,92 & 1,04 & E & $\mathrm{F}$ \\
\hline 8 & 7 & 3675 & 1764 & 0,25 & 0,42 & B & C \\
\hline 9 & 10,5 & 5512,5 & 2646 & 1,07 & 1,11 & $F$ & $F$ \\
\hline 10 & 10,5 & 5512,5 & 2646 & 0,05 & 0,10 & A & A \\
\hline 11 & 10,5 & 5512,5 & 2646 & 0,86 & 0,89 & $E$ & $E$ \\
\hline 12 & 10,5 & 5512,5 & 2646 & 0,42 & 0,66 & C & D \\
\hline 13 & 10,5 & 5512,5 & 2646 & 0,36 & 0,57 & C & C \\
\hline 14 & 14 & 7350 & 3528 & 0,40 & 0,63 & C & D \\
\hline 15 & 10,5 & 5512,5 & 2646 & 0,28 & 0,52 & B & C \\
\hline 16 & 14 & 7350 & 3528 & 0,19 & 0,24 & B & B \\
\hline 17 & 10,5 & 5512,5 & 2646 & 1,10 & 0,93 & $F$ & $E$ \\
\hline 18 & 10,5 & 5512,5 & 2646 & 0,29 & 0,34 & B & C \\
\hline 19 & 10,5 & 5512,5 & 2646 & 0,30 & 0,36 & C & C \\
\hline 20 & 10,5 & 5512,5 & 2646 & 0,14 & 0,07 & B & A \\
\hline 21 & 10,5 & 5512,5 & 2646 & 0,26 & 0,31 & B & C \\
\hline
\end{tabular}

Tabela 4: Nível de serviço.

\subsection{SIMULAÇÃO PRESCRITIVA}

A fim de tentar reduzir o tempo de permanência dos agentes não motorizados (pedestres), inseriu-se um novo semáforo no trecho 7 (Figuras 3 e 7) controlado por botão de travessia (botoeira), indicado pelo retângulo amarelo na Figura 7.

Aliado a isso, deslocou-se o trecho 8 (Figuras 3 e 7) para que as linhas de ônibus de entrada no trecho 1 e saída no trecho 15 (Figuras 3 e 7) pudessem parar no ponto de ônibus próximo ao Shopping Boulevard (Figura 4). Isso porque a maior parte dos pedestres que segue as rotas 1, 3, e 5 (Figura 4) descem no ponto de 
ônibus do Hospital Santa Helena (Figura 4), por falta de opção de linhas (linhas de ônibus ou linhas de desejo) que façam a travessia da malha.

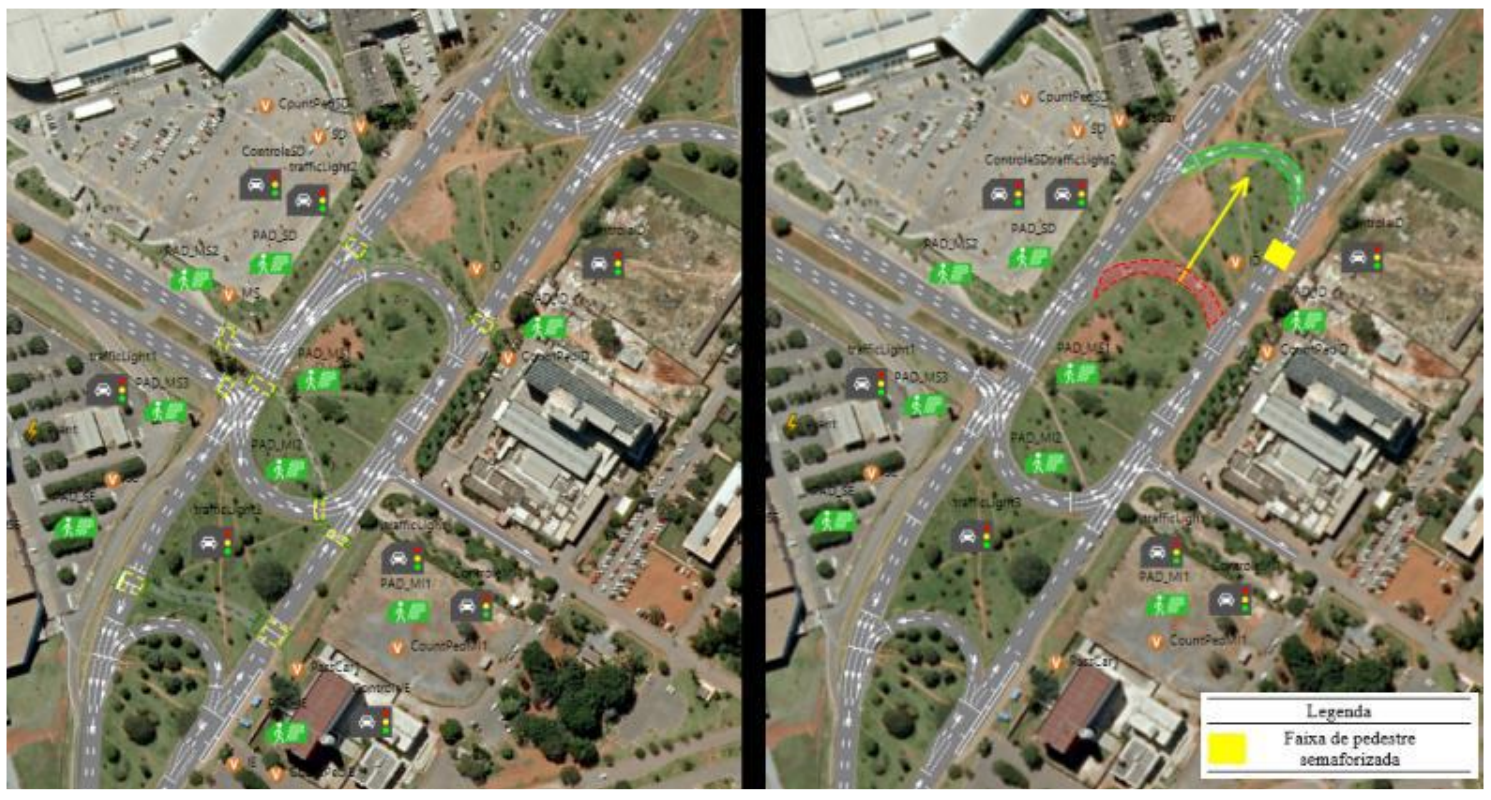

Figura 7: Alterações da estrutura física da malha.

Fonte: CODEPLAN (2014)

Com base nisto, verifica-se que esta alteração apresenta uma redução na demanda de pedestres nas travessias (Tabela 5), o que mostra que com a inserção de moderadores de tráfego (a exemplo das faixas semaforizadas) é possível alcançar maior equilíbrio nos deslocamentos de todos os modos de transporte, sem deixar de levar em consideração o agente mais frágil da cadeia de mobilidade, o pedestre (JACOBS, 2000; GEHL, 2010, PORTUGAL, 2012).

\begin{tabular}{cc}
\hline Agente & Tempo de permanência médio (s) \\
\hline Pedestres & 142,81 \\
Carros & 265,99 \\
Ônibus & 292,72 \\
\hline
\end{tabular}

Tabela 5: Tempo de permanência (Solução)

Como achados, verificou-se que na simulação descritiva o maior tempo médio de espera (Tabela 3) foi dos ônibus $(300,35 \mathrm{~s})$, em seguida dos pedestres $(214,13 s)$ e o menor dos carros $(179,35 s)$, o que ratifica o foco dado aos veículos motorizados individuais. De modo a melhorar o tempo de espera dos pedestres, na simulação prescritiva, procede-se à inserção de uma faixa semaforizada, demandando o deslocamento de cerca de 30 metros do retorno sentido leste- 
oeste (SHLN - Shopping) em direção à Ponte do Bragueto (Figura 7), havendo, assim, a inversão dos tempos entre pedestres $(142,81$ s) e carros $(265,99)$, e para o ônibus sendo pouco significativo $(292,72 s)$ (Tabela 5).

\section{CONCLUSÃO}

Com base no objetivo do trabalho, cabe inferir que é possível realizar intervenções no traçado de vias arteriais, de modo que haja uma melhoria considerável no tempo de percurso e conforto dos agentes não motorizados, e que o aumento do tempo de permanência dos carros, embora maior, ainda assim, seja aceitável, visto que a inserção do semáforo proporciona maior segurança a todos os modos do sistema, principalmente aos pedestres (JACOBS, 2000; GEHL, 2010; PORTUGAL, 2012).

A partir das análises realizadas, pode-se afirmar que mesmo em cidades com uma forma urbana modernista, como Brasília, há soluções que podem ser implantadas sem que se altere a concepção e o tombamento da mesma, e que consiga priorizar os deslocamentos dos agentes mais frágeis da cadeia de mobilidade urbana, no caso, os pedestres.

Cabe, ainda, a recomendação de que sejam realizadas simulações em outras vias de mesmas características para que sejam realizados estudos comparativos, de modo a verificar a eficiência do software em relação a análises que envolvam a confluência entre os modos de transporte motorizados e não motorizados. 


\section{REFERÊNCIAS BIBLIOGRÁFICAS}

ANYLOGIC. Software de modelagem de simulação. Versão 8.2.3. The AnyLogic Company, Brasília, 2018.

BARROS, A.; MARTÍNEZ, L.; VIEGAS, J. How urban form promotes walkability. 2017. Transportation Research Procedia, v. 27, p.133-140.

BRAGA, F. Metodologia para travessias de pedestres em vias arteriais - estudo de caso na W3 Norte. No prelo. Monografia de Especialização (no prelo). Centro Universitário de Brasília - UniCEUB, Brasília, 2017.

CODEPLAN, Governo do Distrito Federal (GDF). Disponível em: $<$ http://ortofoto.mapa.codeplan.df.gov.br/demo/tms> Acesso em: 22 de junho de 2018.

COSTA, L. Relatório do Plano Piloto de Brasília. CODEPLAN/GDF, Brasília, 1991.

GEHL, J. Cidades para Pessoas. Perspectiva, São Paulo, 2010.

HILLIER, B.; HANSON, J. The Social Logic of Space. Cambridge Press, Cambridge, 1984.

JACOBS, J. A Morte e Vida de Grandes Cidades. Martins Fontes, São Paulo, 2000.

KNEIB, E. C. Caracterização de empreendimentos geradores de viagens. Dissertação de Mestrado. PPGT/UnB, Brasília, 2004.

MEDEIROS, V. Urbis Brasiliae. EdUnB, Brasília, 2013.

PORTUGAL, L. Polos Geradores de Viagens orientados a qualidade de vida e ambiental: modelos de taxas de geração de viagens. Interciência, Rio de Janeiro, 2012.

TRB - Transportation Research Board. Highway Capacity Manual. (4a ed.). Washington, D. C, 2000. 